\title{
Wagner model correction under stress
}

\author{
Xiao-Qian Nie ${ }^{\text {a) }}$, Xian-Cheng Zhang ${ }^{\text {b) }}$ \\ Key Laboratory of Pressure Systems and Safety, Ministry of Education, School of Mechanical and Power \\ Engineering, East China University of Science and Technology, Shanghai 200237, China \\ a)xqnie93@163.com \\ b)xczhang@ecust.edu.cn
}

\begin{abstract}
For components that work at high temperatures, the final failure of the components is caused by the complex conditions. Most of the existing life prediction models are based on the failure of the material to withstand creep damage, fatigue damage, and the interaction between the two. In fact, many engineering components will be serviced under the oxygen corrosion environment under external loads. The failure process not only stays in the fatigue, creep and other changes caused by the mechanical properties of the material, the oxidation of the material in high temperature environment will also have a non-negligible impact on the service life of the components.
\end{abstract}

Keywords: high temperature, oxygen corrosion, external loads, failure process, fatigue

\section{INTRODUCTION}

At extreme temperatures, the metal or alloy will inevitably react with the oxygen in the environment, that is, the metal (alloy) is oxidized. The oxidation process generally starts from the surface and forms an oxide film on the surface first. The oxide film of most materials generally has a protective effect on the base material because the presence of an oxide film can block the contact between oxygen and the base material and increase oxidation. The difficulty of the reaction continues to play a role in inhibiting the further oxidation of the material, slowing down the entire failure process and extending the service life. However, when the component is subjected to a load, it may induce cracking, separation, and exfoliation of the oxide film. This is equivalent to destroying the protective function of the oxide film, making the new substrate material have a direct contact with oxygen, and disguised promotion. The progress of the oxidation reaction speeds up the actual oxidation reaction rate. Many studies have shown that the oxidation behavior of metallic materials has a great relationship with its stress state ${ }^{[1,2,3]}$.

In fact, many engineering components will be serviced under the oxygen corrosion environment under external loads. The study of external loads not only stays in fatigue, creep, etc., causing changes in the mechanical properties of the material, but also focuses more on the effects of external loads on the chemical destruction of the material surface. However, in the current study, the exact relationship between stress state and oxide film growth cannot be obtained, and the microscopic mechanism of the effects of high temperature oxidation on fatigue life and creepfatigue life cannot be determined ${ }^{[4]}$.

\section{SAMPLE PREPARATION AND TEST METHODS}

\section{Sample Preparation}

The experimental material alloy used in the research was the second-generation powder superalloy developed in China. Table 1 shows the chemical composition of the alloy. 
TABLE 1. Chemical composition of FGH96 superalloy(wt\%)

\begin{tabular}{ccccccccc}
\hline $\mathrm{Cr}$ & $\mathrm{Al}$ & $\mathrm{Fe}$ & $\mathrm{C}$ & $\mathrm{N}$ & $\mathrm{H}$ & $\mathrm{O}$ & $\mathrm{Ni}$ \\
\hline 15.8 & 2.04 & 12.4 & 3.79 & 0.49 & 3.31 & 2.3 & $\mathrm{Bal}$ \\
\hline
\end{tabular}

\section{Experiment Method}

The loading waveform is shown in Figure 1. The pure fatigue life test (PP), tensile strain load cycle test (CP) and compressive strain load cycle test (PC) were performed separately. The experimental machine is INSTRON8032 electro-hydraulic servo universal material fatigue tester. The test process is total strain control, temperature is $650{ }^{\circ} \mathrm{C}$, test waveform is triangle/trapezoidal wave, strain ratio $R \varepsilon=-1$, strain rate is $0.004 / \mathrm{s}$, strain amplitudes are $1.0 \%, 0.8 \%, 0.7 \%$ and $0.5 \%$, respectively
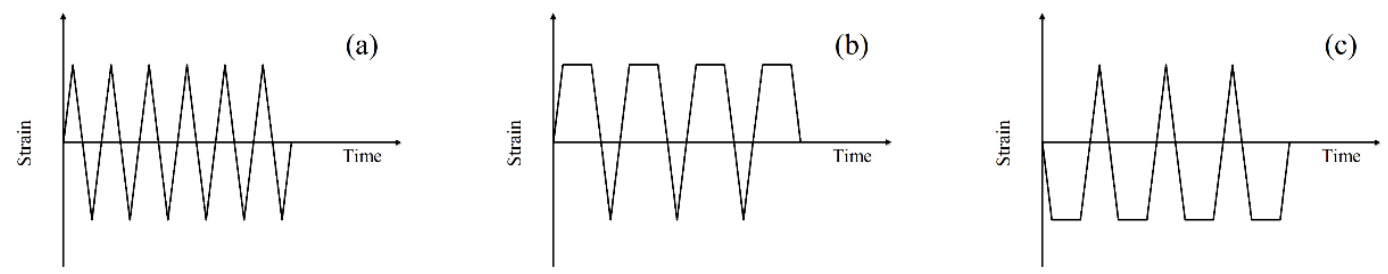

FIGURE 1. Loading waveforms in tests(a) pure fatigue test; (b) fatigue test with load at maximum tensile strain; (c) fatigue test with load at maximum compressive strain

\section{RESULTS AND DISCUSSION}

When studying the oxidation behavior of metals, the Wagner parabolic equation proposed by Wagner is the most common application ${ }^{[5]}$. The Wagner oxidation kinetics model explains the metal oxidation process as follows: When the oxide film is dense, uniform and adhered to the substrate, the growth rate of the oxide film is constrained by the ion diffusion rate. In the semi-steady-state growth state, the diffusion of ions is mainly induced by a chemical potential gradient, and the diffusion flux satisfies the growth of the oxide film without any remaining. Specifically, it can be calculated using the following formula:

$$
\begin{gathered}
h=\sqrt{\mathrm{K}_{\mathrm{P}} \mathrm{t}}(1) \\
\mathrm{K}_{\mathrm{P}}=\frac{1}{t} \int_{0}^{t} D_{\mathrm{o}} \exp \left(\frac{-Q}{R T_{(\mathrm{t})}}\right) d t \#(2)
\end{gathered}
$$

Where $\mathrm{K}_{\mathrm{P}}$ is the parabolic oxidation constant, which is a function of temperature, $\mathrm{D}_{0}$ is the diffusion coefficient in the unstressed state, $\mathrm{Q}$ is the activation energy for oxidation, $\mathrm{R}$ is the gas constant, and $\mathrm{T}_{(\mathrm{t})}$ is the temperature.

Based on Wagner's theory of oxidation kinetics, the diffusion of oxygen in the oxide film is considered to be the main factor controlling the growth of the oxide film. However, in the actual process, in addition to the diffusion behavior of oxygen within the oxide film, the reaction progress and efficiency at the interface between the oxide and the metal also affect the growth behavior of the oxide film.Material researcher Kraftmaker ${ }^{[6]}$ once elaborated the calculation formula of vacancy density based on the principle of thermodynamics of materials in the study of material calculation model. In the stress-free state, the vacancy density is:

$$
\mathrm{C}_{\mathrm{v}}^{0}=\frac{\mathrm{n}}{\mathrm{n}+\mathrm{N}}=\exp \left(\frac{\mathrm{S}_{\mathrm{f}}}{\mathrm{k}}-\frac{\mathrm{E}_{\mathrm{v}}}{\mathrm{kT}}\right) \#(3)
$$

Among them, $\mathrm{C}_{\mathrm{v}}^{0}$ is the vacancy density in the stress-free state, $\mathrm{n}$ is the number of vacancies, $\mathrm{N}$ is the total atomic number, $S_{f}$ is the formation entropy of the vacancy, $E_{v}$ is the formation energy of the vacancy, $k$ is the Boltzmann constant, and $\mathrm{T}$ is the thermodynamic temperature.

. Based on these studies, Evans ${ }^{[7]}$ gives the formula for the variation of vacancy concentration when the material is subjected to external loading:

$$
\mathrm{C}_{\mathrm{v}}=\mathrm{C}_{\mathrm{v}}^{0} \exp \left(\frac{\sigma_{\mathrm{h}} \nabla \mathrm{V}}{\mathrm{RT}}\right) \#(4)
$$


Among them, $\mathrm{C}_{\mathrm{v}}$ is the vacancy density in the presence of stress, $\sigma_{\mathrm{h}}$ is the stress, $\nabla \mathrm{V}$ is the vacancy activation volume, and $\mathrm{R}$ is the gas constant.

Due to the use of existing methods, the activation volume of vacancies within the oxide film is difficult to measure and is replaced by the activation volume of the oxidation reaction, and is approximated by the PillingBedworth ratio (PBR) ${ }^{[8]}$ :

$$
\nabla \mathrm{V}=(\mathrm{PBR}-1) \mathrm{V}_{\mathrm{m}} \#(5)
$$

Where $V_{m}$ is the molar volume of the oxidized metal or alloy.

The stress state in the oxide film is assumed to be the plane stress state, ie, the stress in the direction perpendicular to the interface is zero, all the shear stress is zero, and the in-plane spindle stress is large. Therefore, the relationship between the hydrostatic stress and the internal stress of the oxide film is:

$$
\sigma_{\mathrm{h}}=\frac{2}{3} \sigma_{\mathrm{ox}} \#(6)
$$

In summary, consider the effect of stress state on vacancy concentration and oxidation kinetics under load. The diffusion coefficient in the presence of stress should be added corrections:

$$
\mathrm{A}=\mathrm{e}^{\frac{\sigma_{\mathrm{OX}} \nabla \mathrm{V}}{3 \mathrm{RT}}} \#(7)
$$

On the basis of the Wagner model, the overall oxidation time needs to be resolved. Based on the overall loading time, the effects of the oxidation constants under the action time of the tensile and compressive loads are taken into account, respectively. Pressure plus interference pressure correction coefficient for interference of oxidation:

$$
B=\sqrt{6\left(\frac{t_{c}}{t}\right)^{2}+3\left(\frac{t_{t}}{t}\right)^{2}+\left(\frac{t_{f}}{t}\right)^{2}} \#(8)
$$

In summary, combining equations (7) and (8) with the consideration of different stress and retention factors for the interference of oxidation, the Wagner parabolic equation is revised to:

$$
\begin{gathered}
\mathrm{h}=\mathrm{B} \sqrt{\mathrm{AK_{P } \mathrm { t }} \#(9)} \\
\mathrm{K}_{\mathrm{P}}=\frac{1}{\mathrm{t}} \int_{0}^{\mathrm{t}} \mathrm{D}_{0} \exp \left(\frac{-\mathrm{Q}}{\mathrm{RT}}\right) \mathrm{dt} \#(10) \\
\mathrm{B}=\sqrt{6\left(\frac{\mathrm{t}_{\mathrm{c}}}{\mathrm{t}}\right)^{2}+3\left(\frac{\sigma_{\mathrm{ox}} \mathrm{t}}{\mathrm{t}}\right)^{2}+\left(\frac{\mathrm{t}_{\mathrm{f}}}{\mathrm{t}}\right)^{2}} \#(11)
\end{gathered}
$$

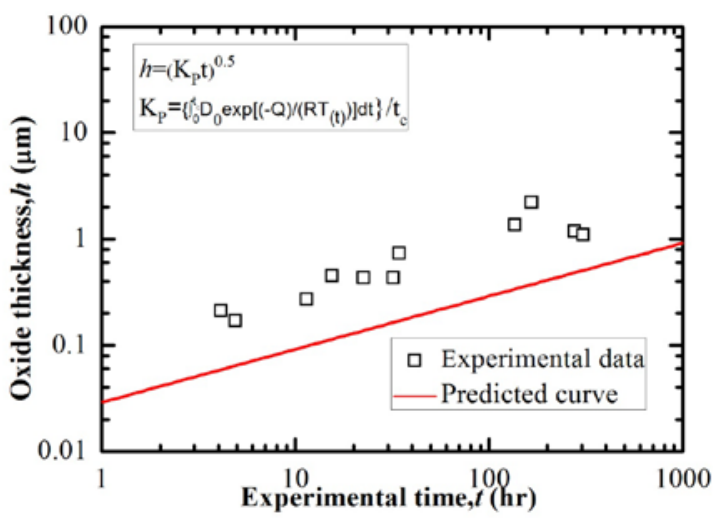

FIGURE 2. At the same strain level and hold time, comparison of the amount of oxidation thinkness of powdery FGH96 powder superalloy under tensile stress and compressive stress at $650{ }^{\circ} \mathrm{C}$

It can be seen from the figure that the oxidation model of Wagner that does not consider the effect of stress is insufficient in the predicted oxidation amount, and the predicted oxidation amount is much lower than the actual oxidation amount. The oxidation time is divided and the Wagner oxidation model under relatively accurate stress 
can be obtained by taking into account the influence of the oxidation constants under the tensile and compressive loading time on the basis of the overall loading time.

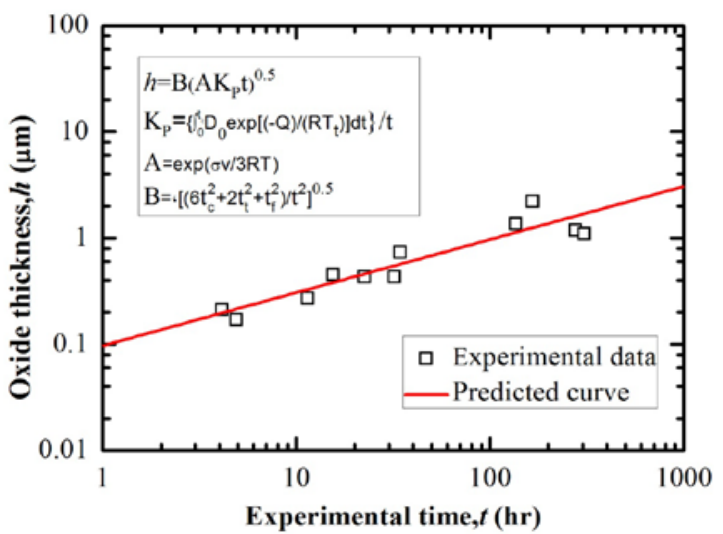

FIGURE 3. At the same strain level and hold time, comparison of the amount of oxidation thinkness of powdery FGH96 powder superalloy under tensile stress and compressive stress at $650{ }^{\circ} \mathrm{C}$

\section{CONCLUSION}

A stress correction term is added on the basis of the Wagner parabolic equation, and the stress correction term is added, ie, the oxidation time is divided, and the oxidation constants under the action time of the tensile and compressive loads are taken into consideration separately on the basis of the overall loading time. The effect of Wagner's oxidation model under relatively accurate stress can be obtained. The modified results show that the accuracy of the prediction of the oxidation amount of the Wagner parabolic equation is improved, which plays a positive role in the development of the oxidation counter-lifespan.

\section{ACKNOWLEDGMENTS}

The authors would like to acknowledge gratefully for the financial support through National Natural Science Foundations of China (51371082, 51322510) and the 111 project. The author X.C. Zhang is also grateful for the support by Shanghai Pujiang Program, Shanghai Technology Innovation Program of SHEITC (CXY-2015-001), and Fok Ying Tung Education Foundation.

\section{REFERENCES}

1. Przybilla W, Schütze M. Role of Growth Stresses on the Structure of Oxide Scales on Nickel at 800 and $900^{\circ} \mathrm{C}$, Oxidation of Metals. 58 (2002) 103-145.

2. Gaillet L, Viennot M, Berger P, et al. Effect of NiO scales on the creep behavior of Ni single crystals at $550^{\circ} \mathrm{C}$, Materials Science \& Engineering A. 332 (2002) 382-391.

3. Li M, Li T, Gao W, et al. Determination of Oxide Growth Stress by a Novel Deflection Method, Oxidation of Metals. 51 (1999) 333-351.

4. Neu R W, Sehitoglu H. Thermomechanical fatigue, oxidation, and Creep: Part II. Life prediction. Metallurgical Transactions A. 20 (1989) 1769-1783.

5. Wagner C. Theoretical Analysis of the Diffusion Processes Determining the Oxidation Rate of Alloys, Journal of tile Electrochemical Society. 99 (1952) 369-280

6. Kraftmakher Y. Equilibrium vacancies and thermophysical properties of metals, Physics Reports.299 (1998) 79-188.

7. Evans H E. Stress effects in high temperature oxidation of metals, Metallurgical Reviews. 40 (1995) 1-40.

8. Xu C, Gao W. Pilling-Bedworth ratio for oxidation of alloys, Materials Research Innovations. 3(2000) 231235. 